\title{
Phonological Structure of Borrowed Words in the Karakalpak Language
}

\author{
Yulduz Makhamatdinovna Shamshetova ${ }^{1}$, Sayora Abilaevna Elmuratova ${ }^{2}$ \\ ${ }^{1}$ Assistant-teacher,Nukus State Pedagogical Institute named after Ajiniyaz, Faculty of Foreign Languages, \\ Department of Russian Language and Literature \\ ${ }^{2}$ Candidate of Philology,Nukus State Pedagogical Institute named after Ajiniyaz, Faculty of Foreign Languages, \\ Department of Russian Language and Literature
}

Email : ${ }^{1}$ yulya911@list.ru, ${ }^{2}$ sayora_1981@mail.ru

\begin{abstract}
:
This article examines the phonological changes in morphemes of borrowings of the Karakalpak language. Study shows of the process of penetration of elements of one language into another. Researchers examined some works and prove that the facts about the transformation of foreign language elements exit in Karakalpak.
\end{abstract}

Key words: phonology, Russian linguists, Turkic linguists, theory of morphonology, research of morphonology.

Article Received: 16th October, 2020; Article Revised: 30th December, 2020; Article Accepted: 08th January, 2021

\section{Introduction}

The study of the process of penetration of elements of one language into another and their existence in the borrowing language has not yet acquired a systematic character. To date, researchers have considered a number of interesting facts on the transformation of foreign language elements. V.A.Vinogradov's work is devoted to the synharmonism and phonology of the word, Diouf Aliou considered the morphonology of Russian prefixes and suffixes in his work [1]. The first works concerning the morphonology of the Turkic languages belong to I. P. Pavlov [2], who characterized the phenomena occurring in the Chuvash language.

\section{The main results and findings}

A special contribution to the morphonology of the Turkic languages, including the Karakalpak language, was made by N.A. Baskakov [3], despite the fact that in his works he focused on general issues of morphonology and did not have a clearly

directed study in this aspect. In the article by D.A. Salikhov [4], the analysis of the morphonology of the Tatar language, or rather the truncation at the base of the word, is given, as an object of a morphological phenomenon.A special contribution to the study of the morphonology of the Azerbaijani language was made by fr.Jalilov [5]. As an object of research, he identified such morphological phenomena as alternation, truncation, overlap, elision, and haplology of phonemes. A. Aigabylov was engaged in the issues of morphonology of the Kazakh language [6], many of his works are devoted to this topic. In Kyrgyz linguistics, the study of morphonological phenomena was carried out by T.Sadykov [7]. The object of his research was the initial forms of morphemes. The morphonology of the Uzbek language is based on the works of A. Nurmanov and A. Abduazizov. In the works of A. Nurmanov [8], the concept of morphemes, the opposition of language units of the same level and the identification of differences between them are revealed. A. 
Abduazizov [9] establishes similarities and differences in the phonetic systems of native foreign languages. Authors conduct a comparative analysis of the phonology of diverse languages. As an object of research, the morphology of the Karakalpak language has not been studied properly, but, like other languages, the Karakalpak language has its own phonetic, grammatical structure. Research has also been conducted in the field of dialectology, the history of the language, which can be the basis for the study of morphonology. The only linguist who was engaged in morphonology as the main kind of his activity is considered to be M. Kudaibergenova [10], who in his works analyzes the morphonological phenomena of the Karakalpak language.

However, they are still fragmented and unsystematic due to insufficient consideration of the materials of related and dissimilar languages in a comparative plan. Overlooked, for example, is the assimilation of foreign language borrowings in the morphological aspect. Of course, the results of morphological changes, i.e. phonetic and phonomorphological, in borrowings will depend, first of all, on how the phonological "sieve" of the borrowing language sifts phonemes and their variants. This linguistic phenomenon can be demonstrated on the material of foreign words that are alien to the Karakalpak language. In the course of the study of Russian loanwords in the Karakalpak languages, there are cases of the existence of parallel orthograms of the same lexemes associated with the variation in their composition of individual graphic designations. For example: Aviation (from French. Aviation, from the Latin avisbird)- aviatsiya-aviaciya, this is due to the fact that from 1994 to 2009, the Karakalpak alphabet was based on a Latin chart consisting of 31 letters, since 2009, changes have been made. The "c" graphic was introduced to denote the Russian "c", and the "ch" graphic was also introduced to denote the "h" [11].

As we can see, the essence of variation is determined by the possibilities of transmitting a single linguistic meaning in several forms or ways. The orthographic variant of borrowing follows from the selfcharacter of the sound system of the donor language and the borrowing language.

It should be noted that when transferring borrowed words to the Karakalpak language, there are discrepancies in their 1) origin, 2) source, 3) spelling and 4) pronunciation.

When investigating the causes of changes in pronunciation, we rely on the overlapping effect of phonological contrasts in the speech flow with phonological oppositions in the language system.

Changes in the phonetic character in the context of the interrelation of languages are reduced to the replacement of some forms by others. They are caused by the presence of foreign phonemes in borrowed words or the incomplete coincidence of sound laws in the two languages. For example, the Karakalpak language is not characterized by a number of combinations of sounds in some words borrowed from the Russian language. Hence, there are fluctuations in their transmission.

However, we are interested in other variants that owe their appearance to the different pronunciation of a foreign word. Here we will talk about the phonomorphological variants that find their expression in the phonetic and morphological dictionaries of such borrowings.

The specificity of written speech often leads to the normative consolidation of phonetically unadapted variants. It should be noted that the vocabulary of the Karakalpak language contains many Russian loanwords on-nation, rendered astsiya or-siua: vulgarization-vul'garizatsiya - vul'garizaciya. Also, in the borrowings, morphemic differences are traced, representing in the form of a peculiar element, the phonetic form of which is not 
associated with any Karakalpak affix, such an element as - tsiya, which goes back to the Russian language.

As the analysis of the scientific literature shows, the possibilities for assimilation of foreign language elements in the Karakalpak language are almost inexhaustible, and the specific forms are different. The degree of assimilation is determined by the time of borrowing, the frequency of its use and the method of borrowing. Most of all, such assimilation is observed in early borrowings that penetrated through oral speech. Some researchers have tried to represent assimilation in the form of a linear sequence. However, as the material we have collected shows, these conditions are not always met. Often, the spelling of borrowings was focused on the Russian spelling norm in violation of the existing norms of the native language-Karakalpak. A clear proof of this is the result of writing borrowed words in-tsiya-siua, despite the different composition of the alphabets: examples. Such a transfer of the word persists for quite a long time, which tells us about the tracing of the phonological phenomenon. Due to this, the affix - siya for a native speaker of the Karakalpak language is not a divisible part.

Phonetic or morphological variation is an unavoidable phenomenon of mastering a foreign language word. Russian Russian words ' precarious state is determined by the competition between the Russian and Karakalpak language rules. In this case, this is a consequence of the lack of mastering the Russian vocabulary. The reason for this situation is the uneven development of the Russian language, both individually and regionally.

If we consider the phonology of the root Mohanem, you can see two different conflicting trends. Supporters of the first position (V. V. Radlov, N. A. Baskakov, J. Denis)it is believed that the root morpheme consists of CGS (C-consonant phoneme, G-vowel phoneme) syllables, which in turn form syllabic morphemes
(C) GC, C G(C), (C)G (C). According to the proponents of the second position (A. N. Kononov, A. M. Shcherbak, B. M. Yunusaliev), the syllable of the root morpheme was open and then these root morphemes were formed from it. To date, linguists have analyzed a considerable number of root phonemes on the material of different languages and provided statistical data accordingly. As for the Karakalpak language, many phonetists have built their research, unfortunately, based on the phonetic patterns of the Russian language. This is due to the fact that the main layer of the vocabulary of the Karakalpak language was made up of Russian loanwords or international words that penetrated through it. And with the independence of the Karakalpak language, Arabisms were used most of all, which greatly affected the phonetic shell of borrowing from the Russian language.

Naturally, it is difficult to immediately give any idea about the syllabic structure of the root morphemes of the Turkic languages. But most researchers adhere to this idea and promote it. One of the proponents of this idea is N. A. Baskakov, who in his work tried to prove that in the Turkic languages the structure of syllables of root morphemes consists of CGC. In his work "Ancient Turkic Dictionary", he cited 709 root morphs, and systematized their syllabic structure as follows [12]:

$$
\begin{aligned}
& \text { C CGC-504-71\% } \\
& \text { (C)GC-107-15,1\% } \\
& \text { CGCC-25-3,6\% } \\
& \text { (C)GCC-14-2,0\% } \\
& \text { CG(C)-18-2,5\% } \\
& \text { (C)G(C)-5-0, } 7 \% \\
& \text { 709-100\% }
\end{aligned}
$$

In Kazakh linguistics, A. K. Khasenova analyzed 230 root morphemes, and their structure is shown properly[13]:

CGC $-179-77,8 \%$

(C)GC-39-17\% -

CGCC-4-1, $7 \%$

(C)GCC-3-1,3\%

$\mathrm{CG}(\mathrm{C})-4-1,7 \%$

(C) $\mathrm{G}(\mathrm{C})-1-0,4 \%$ 


\section{$230-100 \%$}

And in the Uzbek language, statistical studies were conducted in the field of studying root phonemes. It was found that the structure of the morphemes consonant + vowel consists of $49 \%$, and consonant + vowel + consonant is approximately $40 \%$. Abduazizov A. A. writes that these statistics show that the Uzbek language has recently increased syllables with a consonant + vowel phoneme [9]. This type of syllabic phonemes is widely used in world linguistics. It is easy to pronounce, the articulation of the consonant is pronounced together with the vowel.

But some facts suggest the opposite. Therefore, it is necessary to consider the question of the phonemic structure of root morphemes not one-sidedly, but comprehensively.

In the Karakalpak language, only in

interjections there is a root morpheme

\begin{tabular}{|c|c|c|c|c|c|c|c|c|c|c|c|c|c|c|c|c|c|c|c|c|}
\hline & 6 & $\Gamma$ & $F$ & Д & ж & 3 & л & $\mathrm{p}$ & Й & $\overline{\mathrm{y}}$ & $\mathrm{M}$ & $\mathrm{H}$ & $\mathrm{H}$ & $\Pi$ & қ & $\kappa$ & $\mathrm{T}$ & $\mathrm{c}$ & ш & Overall \\
\hline A & - & - & - & - & - & + & + & + & + & + & + & - & + & - & + & - & + & + & + & 11 \\
\hline$\partial$ & - & - & - & - & - & - & - & - & $@$ & - & - & - & - & - & - & - & - & - & - & 1 \\
\hline 0 & - & - & - & - & - & + & + & + & + & - & - & + & + & - & + & - & + & + & - & 9 \\
\hline$\theta$ & - & - & - & - & - & + & + & + & - & - & - & + & - & + & - & - & + & + & + & 8 \\
\hline$y$ & - & - & - & - & - & & + & + & - & + & - & + & - & - & + & - & + & - & + & 7 \\
\hline $\mathrm{Y}$ & - & - & - & - & - & + & + & + & + & - & - & + & - & - & - & - & - & - & + & 5 \\
\hline ы & - & - & - & - & - & - & - & - & - & - & $@$ & - & - & - & + & - & - & + & - & 3 \\
\hline И & - & - & - & - & - & + & + & - & - & - & - & + & - & - & - & - & - & + & + & 5 \\
\hline$E$ & - & - & - & - & - & + & + & + & - & - & + & + & @ & + & - & + & + & + & - & 10 \\
\hline & & & & & & & & & & & & & & & & & & & & 59 \\
\hline
\end{tabular}

First, M. S. Kudaibergenov In this table indicated under the sign $(+)$ that this phoneme exists, and under the sign $(-)$ that it does not exist, ( @ ) the sign indicates that this is an auxiliary morpheme. Secondly, he conducted an analysis of morphemes, which are subject to the phonetic laws of the Karakalpak language. Third, this table includes softening phonemes, which do not include the consonants $/ \mathrm{v} /, / \mathrm{x} /, / \mathrm{x} /, / \mathrm{f} /$.

After analyzing the dictionary of borrowings of K. M. Koshchanov, consisting of more than 2000 words of the Karakalpak language [14], we found only five borrowings with one syllable. consisting of a single phoneme. These are the phonemes $/ \mathrm{a} /, / \mathrm{o} /, / \mathrm{a} /$, which soften when serving the structure of the composition of morphemic phonemes. For example: A, SIZ makeselection (sh.Seitov), Oh, - Dedi atazhanov menin soraganyma...(K. Sultanov).

In the modern Karakalpak language, root morphemes consisting of an open syllable per consonant + vowel are limited. Only rarely found in verb root morphemes, such as ana-mother, ma-take, same-eat. But there are enough root morphemes consisting of a closed syllable glany+ consonant: at-name, ol-on, al-take. For the accuracy of determining such phonemes, you can use the table of Kudaibergenov M. S.[10]
Borrowing with a root morpheme consisting of one open syllable consonant + vowel, then it is just one word: soupRussian dish. Borrowings with a root morpheme consisting of a single closed syllable vowel + consonant, then they include words such as: ar, as, om, oh.

Root morphemes consisting of three phonemes with a closed syllable-vowel + consonant + consonant-are extremely rare in the Karakalpak language. In most cases, the consonant phonemes that follow each other at the end of a word are a sonorous consonant ta deaf consonant, for example: A. Davletov expressed his opinion about some exceptions to the rules of the words 
of the mouth and mouth, where both deaf consonants come at the end of the word [15]. In his opinion, these words are always used in the form of words with additional affixes ust-from the top of something, asty - at the bottom of something.

There are a huge number of very commonly used root phonemes consisting of a consonant + vowel + consonant phoneme. These include: national Academy of Sciences, drone, Saint etc. Many scholars such as suggest that this may be due to the fact that historically Turkic words emerged from such phonemes.

After analyzing these root morphemes on the dictionary of borrowing K. M. Casanova, we came to the following conclusions that can be shown in the numeric ratio of the number of phonemes present ///in morpheme-33, the number present phoneme $/ \mathrm{o} /$ in morpheme-40, the number of phonemes present /// in morpheme- 31 , the number of present $/ y /$ in morpheme-45, the number of available phonemes /Y/in morpheme-36, the number present, the phoneme /s/in morpheme-49, number present Yves morpheme-33, the presence of the phoneme /e/in morpheme-48. M. S. Kudaibergenov gives the same data in his work[10]. The identical result is most likely due to the fact that in recent years dictionaries have been reissued on the basis of old material, the creation of a dictionary is mainly a collective and timeconsuming work that requires a lot of effort and time.
In the dictionary of borrowings by K. M. Koshchanov, we counted more than 95 borrowings with three root morphemes. Of these, phonemes consisting of vowel + consonant + consonant are not frequent. These are the words: ark, acre, act, x. Root morphemes consisting of three phonemes with an open syllable vowel + consonant +vowel they can include borrowings: both (disease), ode. Of course, the vast majority of loanwords, with a root phoneme consisting of a consonant + vowel + consonant phoneme: bis, baz, bak, bas, buk, bor, val, gaz, gol, gen, dok, dot, shower, dune, hall, yod, cue, cube, code, cab, cash, lag, lak, lok, lom, lek, lot, lub, luk, May, myth, mash, mouse, mayor, nas, nil, ned, nep, paul, pan, par, pop, por, pass, pat, pud, rey, rep, cancer (disease), rome, rum, rudder, rus, san, sos, court, sir, cheese, sir, tip, typhoid, tok, tol, tol, tur, tush, fab-, fon, fas, foot, choir, hot, shop, tea, chat, czech, check, chor, shock, ball, chic.

According to our observations, most of the borrowings with three phonemes consist of a consonant deaf + vowel + consonant deaf, as well as a consonant sonor + vowel + consonant deaf. The table below shows this clearly.

\begin{tabular}{|l|l|l|l|l|l|l|}
\hline $\mathrm{C}(\mathrm{c})+\Gamma+\mathrm{C}(\mathrm{c})$ & $\mathrm{C}(\mathrm{c})+\Gamma+\mathrm{C}(\Gamma)$ & $\mathrm{C}(3)+\Gamma+\mathrm{C}(\mathrm{c})$ & $\mathrm{C}(\Gamma)+\Gamma+\mathrm{C}(\mathrm{c})$ & $\mathrm{C}(3)+\Gamma+\mathrm{C}(\Gamma)$ & $\mathrm{C}(\Gamma)+\Gamma+\mathrm{C}(3)$ & $\mathrm{C}(\Gamma)+\Gamma+\mathrm{C}(\Gamma)$ \\
\hline may & Lak & Bor & kiy & bis & kub & kesh \\
\hline Mer & Lok & Val & lom & bas & kod & pop \\
\hline Nil & Lek & Gol & pol & buk & keb & pas \\
\hline Rey & Lot & Gen & pan & dok & sud & pat \\
\hline Rim & lyuk & Dyun & par & dot & fab & sos \\
\hline Rom & mif & Dyun & por & dush & fab & tip \\
\hline rulb & mash & & sir & baz & & tif \\
\hline & mish & & sbr & gaz & & tok \\
\hline
\end{tabular}




\begin{tabular}{|l|l|l|l|l|l|l|}
\hline & Nas & & ser & & & tol \\
\hline & Nep & & tur & & & tolb \\
\hline & Rep & & fon & & & tush \\
\hline & Rak & & shar & & & fas \\
\hline & Rus & & & & & fut \\
\hline & San & & & & & shok \\
\hline & Lag & & & & & shik \\
\hline & Lub & & & & & \\
\hline & Ned & & & & 6 & 15 \\
\hline 7 & 17 & 6 & 12 & 8 & & \\
\hline
\end{tabular}

In a single case, there are borrowings with the structure vowel + vowel + consonant (aut, iud), and on the reverse consonant + vowel + consonant (mio, neo, shchi).

In the modern Karakalpak language, it is quite rare to find words with a morphemic structure of root phonemes with a closed syllable consonant + vowel + consonant. In most cases, the consecutive consonants consist of sonorants, and the final consonant phoneme is always deaf. For example: Kant - sugar cake -four, the cake pull, etc.r.

\section{Conclusion}

From the examples above, most of the words end with the consonant phoneme /t/ - deaf. There are also onomatopoeic root morphemes consisting of closed syllables. They end with the phoneme /n/: - shlyap, sholp-smack, gurp-berdysh, and others. In the borrowings that have penetrated into the Karakalpak language from Arabic and Farsi, there are 4 root morphemes in their structure -consonant + vowel + consonant: dost-friend, caste - for evil, rast - truth. When these words are translated into Karakalpak, the final / $/$ is truncated: dos, ras, cas, but it should not be noted that when conjugated in cases, the truncated / $t$ / is attached to the bases in the form of an affix: dostym, kasting, dostym, etc.the exception is the word race. In our opinion, this is due to the prosthetics of sounds, which requires a change in the sound composition of speech.

The Karakalpak language has many loanwords, the structural root morpheme of which consists of 4 phonemes. As a result of the analyzed pain sensations. Some have noticed the same pattern in borrowings coming from others, consonants consist of sonorants, and the final consonant phoneme is always deaf, for example: bolt, bank, bow, bow, bow, screw, coat of arms, salvo, probe, umbrella, lars, etc.

Separately, it should be noted that words with the structural morpheme consonant + vowel end in the vowel phoneme /a/: base, beta, vase, vienna, dacha, dina, Dina, dune, zone, lava, llama, lupa, etc.

In the Karakalpak language, there are other variants of root morphemes. They were formed under the influence of external and internal historical influences on the language structure. First, affixes were attached to the root morpheme, which, as a result of internal changes, lost their boundaries and became a single root structure that cannot be distinguished. In linguistics, this phenomenon gave rise to the first and second degree of the root. For example: pisi -saw, gamer -rain, somisCervelo etc., which consist of two affixes. We can determine this based on the etymological choice. Modern Karakalpak language used in these words Yrys, ish, y function affixal morphemes, for example: other, alir, I, II, III, etc. R, in which they perform the role of affixal morphemes. Secondly, due to external influences on the language structure, borrowing lexical material from other languages leads to a change in the phonological structure of root morphemes. 


\section{References}

[1] Diouf Aliu "Morphonology of Russian prefixes and suffixes" abstract for the degree of Candidate of Philological Sciences Moscow 2011.

[2] Pavlov I. P. A brief outline of the morphonology of the modern Chuvash language.- In the book: Chuvash language literature and folklore. Issue. November 4, 1974.

[3] Baskakov A. Historical and typological phonology of the Turkic languages. M.: tip.: Nauka, 1979.

[4] Salikhova D. A. About one morphonological phenomenon in the Tatar language. / / Zh. Sovetskaya turkologiya. 1986. No. 5 from 56-60

[5] Jalilov F. Morphology of the Azerbaijani language. Abstract for the degree of Doctor of Philology-Baku: 1989

[6] Aigabulov A. Morphonology of the Kazakh language. - Almaty: Art. 1995.

[7] Sadykov. T. Theoretical foundations of Kyrgyz phonology and morphonology. - Abstract of the Doctor of Philology. Almaty, 1995.

[8] Nurmonov A. Phonology and morphonology of the Uzbek language.Tashkent, 1990

[9] Abdurazizov A. A. Phonology and morphonology of the Uzbek language.Tashkent. 1992g.

[10] Kudaibergenova M. Morphonology of the Karakalpak language. - Tashkent, 2006.

[11] Session of 2009 of the Supreme Council of the Republic of Karakalpakstan.

[12] Baskakov N. A. Historical and typological morphology of the Turkic languages, - Moscow, 1979

[13] Khasenova A. K. Derivative verbal bases of the Kazakh language. AlmaATA, Kazakh SSR. 1959

[14] Koshchanov K. M. Karakalpak orthographic dictionary of the Uzbek language. - Nokis, 2013
[15] Dauletov A. The Cecil dialect of the modern Karakalpak language Adebebi. - Nokis Bilim B. 99

[16] Shamshetdinovich, N. A. (2020). Changes In The Socio-Political Vocabulary Of Karakalpak Language. European Journal of Molecular \& Clinical Medicine, 7(6), 2395-2402.

[17] Doniyorov, A., Kariev, A., Aminov, H., \& Karimov, N. (2021). The Level of Study of the Religious Image of Mavarounnahr in the IX-XII Centuries. Journal of Contemporary Issues in Business and Government Vol, 27(1). 